\section{SOI: $1.1 / \mathrm{TAS} \quad$ DOI: $10.15863 / \mathrm{TAS}$ \\ International Scientific Journal Theoretical \& Applied Science}

p-ISSN: 2308-4944 (print) $\quad$ e-ISSN: 2409-0085 (online)

Year: 2017 Issue: $06 \quad$ Volume: 50

Published: 17.06.2017 $\quad$ http://T-Science.org
Vadim Andreevich Kozhevnikov

Senior Lecturer

Peter the Great St. Petersburg Polytechnic University vadim.kozhevnikov@gmail.com

Oleg Yurievich Sabinin

Candidate o fEngineering Sciences, Associate Professor Peter the Great St. Petersburg Polytechnic University olegsabinin@mail.ru

Julia Efimovna Shats student

Peter the Great St. Petersburg Polytechnic University

julia7476@gmail.comn

SECTION 4. Computer science, computer engineering and automation.

\title{
LIBRARY DEVELOPMENT FOR CREATING BOTS ON SLACK, TELEGRAM AND FACEBOOK MESSENGERS
}

Abstract: Article contains analyze of existing libraries for messenger bot creation. Also this article describes creation of library that take into consideration advantages and disadvantages of existing solutions.

Key words: Bot, library, software development, Java, Telegram, Facebook, Slack, messenger.

Language: English

Citation: Kozhevnikov VA, Sabinin OY, Shats JE (2017) LIBRARY DEVELOPMENT FOR CREATING BOTS ON SLACK, TELEGRAM AND FACEBOOK MESSENGERS. ISJ Theoretical \& Applied Science, 06 (50): 59-62.

Soi: http://s-o-i.org/1.1/TAS-06-50-4 Doi: crossef https://dx.doi.org/10.15863/TAS.2017.06.50.4

UDC 004.4'2

\section{Introduction}

In nowadays more and more people are using messengers. Messenger is a desktop, web, or mobile application for communication over the internet. It must be said that the concept of communication over the internet does not imply only text messaging. Modern messengers in addition to messaging implement voice and video, file sharing, web conferencing. [1]

Today companies are paying special attention to instant messengers, which are becoming serious competitors to other mobile applications. This is facilitated by chatbots conversational-program, which are already near to become full-fledged interlocutors and assistants. They help to learn a news, exchange rates, order goods, pick up a suitable flight, music, book, and even can act as a distance teacher.

\section{Motivation}

The purpose of this work is to develop a library that will allow developers to create bots for instant messengers such as Slack, Facebook Messenger, Telegram in Java.
There is a large number of users that have difficulties installing a set of mobile applications for every company. Analyzing this situation, many companies come to the conclusion that such users are more likely to use one messenger with several chatbots that replace multiple applications. Because each person uses what is more suitable for him, companies need to support as many platforms as possible, thereby increase the number of clients. Therefore, it would be simpler to be able to communicate with users on multiple platforms without developing for each platform. Hence, there is a demand for existing libraries for fast and simple chatbots development. Therefore, the main task for us was the creation of the library that supports Slack, Facebook Messenger, Telegram platforms. [8]

\section{Implementation}

Chat bots can be developed in any programming language with which you can create a web API. The back-end receives the message, thinks what to answer, and returns the response to the user. 
For the library that must run on multiple platforms, we need to choose appropriate language. Java is one of most popular language that can run on a huge number platforms. (By Tiobe, PyPl and IEEE Spectrum)

API (application programming interface) is set of classes, procedures, functions, structures and constant provided by application, library, service or operation system for use in external software. In this case, the API is provided to developers in the public domain.

Your web server will install so-called webhooks - URL-based connections between your bot and the chat platform. There are two mutually exclusive ways of receiving updates for bot - the getUpdates method on one hand and Webhooks on the other. Incoming updates are stored on the server until the bot receives them either way, but they will not be kept longer than 24 hours. Webhooks will allow you to safely send and receive messages through simple HTTP requests. [5, 6]

Our library will allow developers to call Java methods to send and receive data from messengers.

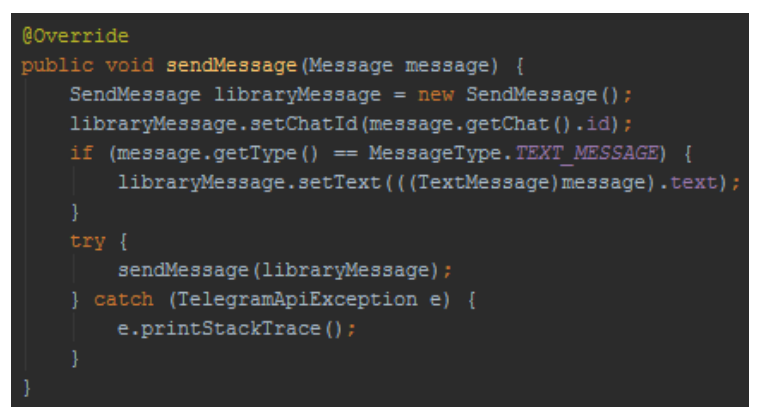

Figure 1 - Sending message demonstration.

\section{Platforms features}

Each platform has its own individual characteristics and features, which must be taken into account. Examples of features:

1. Telegram support new types of input, keyboards that integrated into a message.

Unlike the regular keyboard, clicking on the button of the integrated keyboard will not send messages to the bot - instead, the data will be transferred in the background, which mirrors the interaction with a normal application. [2]

2. Facebook messages can be either just text or Structured Text, which are divided into:

$\square$ button:

This type is used to send messages, which require user response.

Buttons can be one of two types:

- Sending response to bot;

- Redirecting to internet address;

$\square$ generic:
Elements are intended to send cards of goods or other items having a similar structure.

Each member may have title, subtitle, description, image and buttons.

$\square$ receipt:

A receipt may contain information about goods, cost, delivery address, discounts. [3]

3. Slack allows you to use additional types of keyboards and mark individual user messages. [4]

\section{Overview of existing libraries}

Already exist a sufficient number of libraries that implement the integration of messenger APIs to create bots on various programming languages. But we did not find any that would unite these popular platforms in one, with full functionality, and would be implemented in the Java language. (Table 1) 


\begin{tabular}{|c|c|c|c|c|c|c|}
\hline Impact Factor: & $\begin{array}{l}\text { ISRA (India) } \\
\text { ISI (Dubai, UAF } \\
\text { GIF (Australia) } \\
\text { JIF }\end{array}$ & $\begin{array}{l}=1.344 \\
=0.829 \\
=0.564 \\
=1.500\end{array}$ & $\begin{array}{l}\text { SIS (USA) } \\
\text { PИНЦ (Russia } \\
\text { ESJI (KZ) } \\
\text { SJIF (Morocco }\end{array}$ & $\begin{array}{l}=0.912 \\
=0.234 \\
=3.860 \\
=\mathbf{2 . 0 3 1}\end{array}$ & $\begin{array}{l}\text { ICV (Poland) } \\
\text { PIF (India) } \\
\text { IBI (India) }\end{array}$ & $\begin{array}{l}=6.630 \\
=1.940 \\
=4.260\end{array}$ \\
\hline
\end{tabular}

Compare existing and existing libraries.

Table 1

\begin{tabular}{|c|c|c|c|}
\hline \multicolumn{4}{|c|}{ Libraries } \\
\hline Our library & BotKit & Claudia Bot Builder & Universal Bot Framework \\
\hline \multicolumn{4}{|c|}{ Programming languages } \\
\hline Java & Java-Script & Java-Script & JavaScript \\
\hline \multicolumn{4}{|c|}{ Supported systems } \\
\hline $\begin{array}{c}\text { Slack, } \\
\text { Face-book Mes-senger, } \\
\text { Tele-gram }\end{array}$ & $\begin{array}{c}\text { Slack, } \\
\text { Face- } \\
\text { book Mes- } \\
\text { senger, Twilio, } \\
\text { Micro-soft Bot } \\
\text { Frame-work }\end{array}$ & $\begin{array}{c}\text { Facebook Mes- } \\
\text { senger, Slack, Skype, } \\
\text { Viber, Telegram, } \\
\text { Twilio, Amazon } \\
\text { Alexa, Line, Kik, } \\
\text { GroupMe }\end{array}$ & $\begin{array}{c}\text { Facebook } \\
\text { Messenger,Telegram, Kik, } \\
\text { Skype }\end{array}$ \\
\hline \multicolumn{4}{|c|}{ Targeted } \\
\hline Develo-pers & $\begin{array}{l}\text { Deve-lopers and } \\
\text { ordi-nary users }\end{array}$ & Develo-pers & Developers \\
\hline \multicolumn{4}{|c|}{ Объединение интерфейсов } \\
\hline Full support & Full support & $\begin{array}{c}\text { No support for } \\
\text { additional features }\end{array}$ & $\begin{array}{l}\text { No support for additional } \\
\text { features }\end{array}$ \\
\hline \multicolumn{4}{|c|}{ Full functionality support } \\
\hline Full support & Full support & Full support & $\begin{array}{c}\text { No support for additional } \\
\text { features. }\end{array}$ \\
\hline
\end{tabular}

It should be noted that in this table there is no comparison with open-source projects that implement the work in the java language separately for single platforms. Since they have a different task.

\section{Testing}

After the library was implemented, testing was performed on supported platforms. (Fig.2) For the tests, it was decided to create a bot that audits user actions in the PostgreSQL DBMS using created library [7].

The server was implemented through the Open Server with the PostgreSQL module. To work directly with the DBMS was used PgAdmin. [9]

The test bot responds to commands entered by the user.

After starting the bot, it connects to the server log file and starts tracking changes. Once a new entry is added to the log file and the administrator enters command the bot immediately send the message with event description.

With the command "/find_action" you can tell the bot what events you want to find in logs. For example, the command "/find_action select" tells the bot to send data about the select requests being executed.

For example "/find_composite user1 select" - will output of select operations performed by a specific user (user1).

Also, it is possible to receive error notifications. Displaying of the necessary errors occurs through the command "/find_warning".

If you need to use a different log location you can specify it using the command "/setlog" followed by the path to the server. The path can be specified in Windows style (with backslashes) and in Unix style (with regular slashes). The path will be converted to the paths on which OS the PostgreSQL server is located. Also, the "/find" command is available for the database administrator, which is an extremely flexible way of finding specific records in the log. As arguments in this command you can use time intervals, types of records (select, insert, start, stop, etc.), the duration of the action. In the further development, additional opportunities will be added to this search.

With the development of the library, the bot will get a more user-friendly interface using buttons and lists. 


\begin{tabular}{l|lrl|l|ll} 
& ISRA (India) & $=\mathbf{1 . 3 4 4}$ & SIS (USA) & $=\mathbf{0 . 9 1 2}$ & ICV (Poland) & $=\mathbf{6 . 6 3 0}$ \\
Impact Factor: & ISI (Dubai, UAE) $=\mathbf{0 . 8 2 9}$ & PUHU (Russia) $=\mathbf{0 . 2 3 4}$ & PIF (India) & $=\mathbf{1 . 9 4 0}$ \\
& GIF (Australia) & $\mathbf{0 . 5 6 4}$ & ESJI (KZ) & $=\mathbf{3 . 8 6 0}$ & IBI (India) & $\mathbf{4 . 2 6 0}$
\end{tabular}
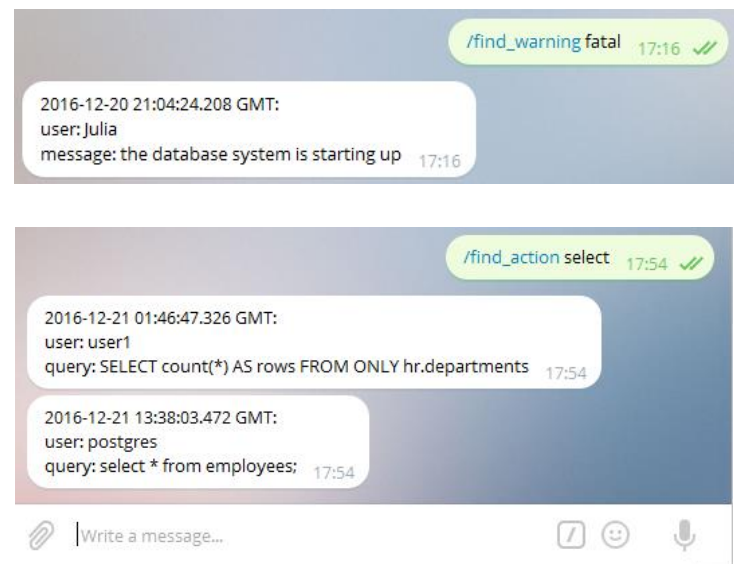

Figure 2 - Demonstration the work one of the test bots on the Telegram platform.

\section{Practical significance}

Created library is aimed at developers, who need frequent dispatches for messengers various platforms. Because, using the library, they have the opportunity not to create a separate program for each platform, but make the dispatch immediately to selected platforms, through several lines of code.

Companies that need such mailing fair amount, reiterate the importance of the development using this or similar libraries.

\section{Conclusion}

A ready-to-use Java library was created. This library allows developers create bots within the unified system for Slack, Telegram and Facebook platforms. In the future, it is planned to add new platforms, as well as to facilitate development by adding auxiliary design patterns for bots.

\section{References:}

1. Obzor Messendzherov. Available: http://www.voipoffice.ru/tags/messendzhery/. (Accessed: 07.06.17) Telegram.

Available: https://core.telegram.org/bots/api. (Accessed: 07.06.17)

3. API Facebook. Available: https://developers.facebook.com/docs/messenge r-platform. (Accessed: 07.06.17)

4. API Slack. Available: https://api.slack.com/botusers. (Accessed: 07.06.17)

5. Java Documentation. Available: http://www.oracle.com/technetwork/java/javase /documentation/index.html.

(Accessed: 07.06.17)

6. Massovaja rassylka. Available: https://smsmanager.ru/info/massovaya_rassylka_cherez_w hatsapp_viber_rassylka/. (Accessed: 07.06.17)

7. PostgreSQL Documentation. Available: https://www.postgresql.org/. (Accessed: 07.06.17)

8. Obzor chat-revolyucii. Available:: http://rb.ru/longread/bots-are-the-new-apps/ (Accessed: 07.06.17)

9. OpenServer. Available: https://ospanel.io/. (Accessed: 07.06.17) 